\title{
Long-term Survival and Reproduction in a North American River Otter (Lontra canadensis) with an Intraperitoneal Radio-Transmitter
}

\author{
Jennifer A. Bohrman, ${ }^{1}$ Sadie S. Stevens, ${ }^{1,2}$ and Thomas L. Serfass ${ }^{1,3}$ \\ ${ }^{1}$ Department of Biology and Natural Resources, Frostburg State University, Frostburg, Maryland 21532 USA \\ ${ }^{2}$ Department of Environmental Conservation, University of Massachusetts, Amherst, Massachusetts 01003 USA \\ ${ }^{3}$ Corresponding author (email: tserfass@frostburg.edu)
}

Bohrman, Jennifer A., Sadie S. Stevens, and Thomas L. Serfass. 2011. Long-term survival and reproduction in a North American River Otter (Lontra canadensis) with an intraperitoneal radio-transmitter. Canadian Field-Naturalist 125(3): 252-254.

Intraperitoneal implantation of radio-transmitters is a useful method of monitoring free-ranging aquatic and semi-aquatic mammals; however, some researchers are concerned about the physiological effects of such implants. Few studies have investigated the long-term consequences of intraperitoneal implants on survival or reproductive performance. An adult female North American River Otter (Lontra canadensis) surgically equipped with an intraperitoneal radio-transmitter and released in northwestern Pennsylvania in June 1990 as part of a reintroduction project was killed in March 1999. The North American River Otter was estimated to be 10 years old and was pregnant with two fetuses at the time of her death. Our observation suggests that wild North American River Otters surgically equipped with intraperitoneal radio-transmitters can live long after implantation of the radio-transmitter and continue to reproduce successfully.

Key Words: intraperitoneal, North American River Otter, Lontra canadensis, radio-telemetry, radio-transmitter, reproduction, survival.

Radio-telemetry is one of the most common methods of monitoring translocated animals following release into an area. Several different types of radio-transmitters may be used, depending on factors such as cost, invasiveness, and species morphology and behavior. For aquatic and semi-aquatic mammals, intraperitoneal radio-transmitters are considered particularly practical biotelemetry devices (Smith and Whitney 1977; Melquist and Hornocker 1979; Reid et al. 1986; Horning et al. 2008) because, unlike radio-collars and harnesses, they are appropriate for the lifestyle and body shape of various species (Garshelis and Siniff 1983; Reid et al. 1986; Rado and Terkel 1989; Van Vuren 1989). However, several complications can potentially result from surgery and implantation of intraperitoneal radio-transmitters, including infection, incision dehiscence, and blockage of internal organs. Moreover, biologists are often concerned about the potential effects of intraperitoneal transmitters on long-term survival, growth, and reproduction (e.g., Van Vuren 1989).

Several studies have investigated the effects of intraperitoneal radio-transmitters on survival and reproduction in aquatic and semi-aquatic mammals (Reid et al. 1986; Horning et al. 2008). Ralls et al. (1989) found no complications associated with intraperitoneal implantation of radio-transmitters in adult Sea Otters (Enhydra lutris) and documented normal reproductive performance in females. Similarly, Horning et al. (2008) studied captive California Sea Lions (Zalophus californianus) and Steller Sea Lions (Eumetopias jubatus) that had been surgically equipped with radio-transmitters and tracked them post-release. After observing low morbidity and zero mortality, Horning et al. (2008) concluded that intraperitoneal radio-transmitters are viable radio-tracking devices.

Reid et al. (1986) assessed the reproductive performance of 7 adult female North American River Otters equipped with intraperitoneal radio-transmitters. Six of the North American River Otters in their study were pregnant at the time of implantation, and they progressed successfully through parturition, with 2 of the females giving birth again in the following season. No adverse effects of the implants were documented at any stage of the reproductive cycle (Reid et al. 1986).

Hernandez-Divers et al. (2001) investigated survival and reproduction in 22 North American River Otters surgically equipped with intra-abdominal radio-transmitters and released in western New York. Although 2 of the North American River Otters experienced surgical complications, both recovered. Three individuals died within the first year of monitoring (1 from an automobile collision and 2 from unknown causes); the remaining 19 North American River Otters in their study established new home ranges. No reproduction was documented during the post-release radio-telemetry monitoring period; however, biologists subsequently observed a pair of the reintroduced North American River Otters in a den with young and received reports of other released individuals having successfully reproduced.

Despite the concern that intraperitoneal radio-transmitters may be harmful, long-term data are not available for most studies of animals surgically equipped with a transmitter. As a result of the relatively short battery life of traditional internal radio-transmitters, researchers cannot generally monitor survival or repro- 
ductive performance for periods longer than three years (Horning et al. 2008). We present a case study of a North American River Otter that carried an intraperitoneal radio-transmitter for nearly 10 years and successfully reproduced.

From 1982 to 2003, 153 North American River Otters were reintroduced into areas in Pennsylvania where the species had been extirpated. Several of the North American River Otters were surgically equipped with intraperitoneal radio-transmitters prior to release (Serfass et al. 1996). In March 1999, a North American River Otter surgically equipped with an intraperitoneal radio-transmitter (field ID: TC-1-99a) was accidentally killed near Kellettville, Pennsylvania $\left(41.55^{\circ} \mathrm{N}\right.$, $79.26^{\circ} \mathrm{W}$ ), approximately $3 \mathrm{~km}$ from her release site, by a fur trapper using a \#330 Conibear ${ }^{\circledR}$ trap (Oneida Victor, Cleveland, Ohio) set for American Beaver (Castor canadensis).

The North American River Otter was originally captured in New York in June 1990 by a trapper and was purchased from the trapper. She was then held in a lab for 14 days to facilitate medical evaluations and surgery to implant a radio-transmitter. She weighed $5.4 \mathrm{~kg}$. On 22 June 1990, TC-1-99a was sedated using an intramuscular injection of ketamine hydrochloride (Serfass et al. 1993), and a region of her abdomen was shaved in preparation for surgery. The radio-transmitter (IMP/ 200/L, Telonics, Mesa, Arizona) was inserted into her peritoneal cavity through a 4-cm lateral skin incision. A lateral approach was chosen rather than a ventral approach because of North American River Otters' habit of dragging their abdomen along the ground (Serfass et al. 1993). In June 1990, TC-1-99a was 1 of 4 North American River Otters to be surgically equipped with an intraperitoneal radio-transmitter and released at Tionesta Creek $\left(41.61^{\circ} \mathrm{N}, 79.15^{\circ} \mathrm{W}\right)$ in northwestern Pennsylvania. Radio-telemetry data collected from 29 June 1990 to 5 March 1991 indicated that TC-1-99a remained within $7 \mathrm{~km}$ upstream and $30 \mathrm{~km}$ downstream of her release site post-release.

The carcass of TC-1-99a was retrieved in March 1999, and a necropsy was conducted. The necropsy included inspecting the digestive tract for food content, checking for ear tags, evaluating the overall physical condition (weight, condition of teeth, etc.), and extracting the lower canines for cementum aging by a commercial laboratory (Matson's Laboratory, Milltown, Montana). The North American River Otter weighed $5.2 \mathrm{~kg}$. Her radio-transmitter remained where it had been inserted in the mid to caudal portion of the abdominal cavity and was surrounded by the omentum. There was no evidence of adhesion, inflammation, or localized infection. Because TC-1-99a's ear tags were no longer present, her radio-transmitter was sent back to the manufacturer so that she could be identified by her radio-transmitter's frequency. Both her upper and lower canines were worn to the incisor level. Cemen- tum aging of the lower canines estimated her to be 10 years old ( \pm 1 year). At the time of her death, she was pregnant with two fetuses. Inspection of the digestive tract revealed a poorly masticated prey content of 7 Smallmouth Bass (Micropterus dolomieu) and approximately 20 Smoothbelly Darters (Etheostoma spp.).

Our information represents the first long-term data on survival and reproduction of a wild North American River Otter surgically equipped with an intraperitoneal radio-transmitter. At 10 years old, TC-1-99a was near the maximum reported life span of a wild North American River Otter, reported by Kruuk (2006) as 14 years. Her canines were severely worn, also indicating her age as old. TC-1-99a appeared to be in good health, and there were no indications of complications associated with her implant. Despite her age, TC-1-99a was reproductively active. TC-1-99a's age and pregnancy demonstrate that her radio-transmitter implant introduced no detriment to her longevity or reproductive performance. Our observations suggest that intraperitoneal radio-transmitters may not disrupt the life history characteristics of North American River Otters, lending more support to their efficacy as biotelemetry devices.

\section{Acknowledgements}

We thank F. Felbaum, J. Hassinger, and A. Hayden for support and guidance during release phases of the Pennsylvania River Otter Reintroduction Project and G. Kollias, A. Gutleb, T. S. Jung, and D. G. Reid for comments that improved this note.

\section{Literature Cited}

Garshelis, D. L., and D. B. Siniff. 1983. Evaluation of radiotransmitter attachments for sea otters (Enhydra lutris). Wildlife Society Bulletin 11: 378-383.

Hernandez-Divers, S. M., G. V. Kollias, N. Abou-Madi, and B. K. Hartup. 2001. Surgical technique for intraabdominal radiotransmitter placement in North American river otters (Lontra canadensis). Journal of Zoo and Wildlife Medicine 32: 202-205.

Horning, M., M. Haulena, P. A. Tuomi, and J. E. Mellish. 2008. Intraperitoneal implantation of life-long telemetry transmitters in otariids. Wildlife Research 34: 1-6.

Kruuk, H. 2006. Otters: Ecology, Behaviour and Conservation. Oxford University Press, New York, New York, USA.

Melquist, W. E., and M. G. Hornocker. 1979. Development and use of a telemetry technique for studying river otter (Lontra canadensis). Proceedings of the International Conference for Wildlife Biotelemetry 2: 104-114.

Rado, R., and J. Terkel. 1989. A radio-tracking system for subterranean rodents. Journal of Wildlife Management 53: 946-949.

Ralls, K. D., B. Siniff, T. D. Williams, and V. B. Kuechle. 1989. An intraperitoneal radio transmitter for sea otters (Enhydra lutris). Marine Mammal Science 5: 376-381.

Reid, D. G., W. E. Melquist, J. D. Woolington, and J. M. Noll. 1986. Reproductive effects of intraperitoneal transmitter implants in river otters. Journal of Wildlife Management 50: 92-94. 
Serfass, T. L., R. L. Peper, M. T. Whary, and R. P. Brooks. 1993. River otter (Lontra canadensis) reintroduction in Pennsylvania: pre-release care and clinical evaluation. Journal of Zoo and Wildlife Medicine 24: 28-40.

Serfass, T. L. Brooks, R. P., Swimley, T. J., Rymon, L. M., and A. H. Hayden. 1996. Considerations for capturing, handling, and translocating river otters. Wildlife Society Bulletin 24: 25-31.
Smith, H. R., and G. D. Whitney. 1977. Intraperitoneal transmitter implants - their biological feasibility for studying small mammals. Proceedings of the International Conference for Wildlife Biotelemetry 1: 109-117.

Van Vuren, D. 1989. Effects of intraperitoneal transmitter implants on yellow-bellied marmots. Journal of Wildlife Management 53: 320-323.

Received 5 June 2011

Accepted 28 September 2011 